Roughly estimated, the incidence of mania in our cohort is 1.7 per 100000 per year. In Dublin the annual incidence of mania for the age group 18-29 was 12.9 per 100000 . In London the respective incidence rate was 7.6 and in Aarhus 5.0 per 100000 (Daly et al, 1995). The finding suggests that the incidence of mania is very low in northern Finland.

Daly, I., Webb, M. \& Kaliszer, M. (1995) First admission incidence study of mania, 1975-1981. British Journal of Psychiatry, 167, 463-468.

KesKImÄKı, J. \& ARo, S. (1991) Accuracy of data on diagnoses, procedures and accidents in the Finnish hospital discharge register. International Journal of Health Science, 2, 15-21.

Rantakallio, P. (1988) The longitudinal study of the Northern Finland birth cohort of 1966. Pediatric and Perinatal Epidemiology, 2, 59-88.

J. VeIJOLA

P. RÄSÄNEN

University of Oulu

M. ISOHANNI

Kajaanintie 43

90210 Oulu

Finland

University of Kuopio

Finland

J. TIIHONEN

\section{Seasonality of birth in Western Australia}

SIR: McGrath et al (1995) examined seasonality of birth of patients with schizophrenia in a southern hemisphere data set. They report that the quarterly birth distribution of patients differed significantly from the estimated general population distribution. Given the paucity of such studies in the southern hemisphere, we report our experience of seasonality of birth in Western Australia.

We confined our analyses to patients born in Western Australia (total general population in 1960 in the vicinity of 700000 ) between 1950 and 1960 , who were recorded as having an in- or out-patient contact with the comprehensive Western Australia Mental Health Register, attracting an ICD-9 diagnosis of schizophrenia or related disorders (ICD-9 295.0-295.9, $n=1186$ ).

Following the methodology of McGrath et al (1995), patients were grouped into quarters depending on their date of birth: January to March; April to June; July to September; and October to December. The counts for these quarters were 303, 300, 296 and 287 respectively. Using monthly birth numbers for Western Australia, as recorded by the Australian Bureau of Statistics to determine the proportions of births in each quarter $(24.09 \%, 25.08 \%, 25.27 \%$ and $25.56 \%$ in quarters one to four respectively), the expected number of schizophrenia births for each of the four quarters was estimated $(285.7,297.5,299.7$ and 303.1 for the first to fourth quarters respectively). A $\chi^{2}$ analysis did not reveal any significant difference between the schizophrenia births and the general population $\left(\chi^{2}=1.97\right.$, d.f. $\left.=3, P=0.58\right)$. Further analyses did not reveal significant differences between female schizophrenia births and the general female population $\left(\chi^{2}=2.01\right.$, d.f. $=3$, $P=0.57)$ nor between male schizophrenia births and the general male population $\left(\chi^{2}=3.01\right.$, d.f. $=3$, $P=0.39$ ).

Thus, our results fail to replicate the findings of McGrath et al (1995). A possible explanation for the disparity is that we confined ourselves to a single decade (hence the relatively low number of patients). However, restriction to Western Australia births allowed more accurate estimates of expected numbers of cases.

McGrath, J. J., Welham, J. L. \& Pemberton, M. R. (1995) Month of birth, hemisphere of birth and schizophrenia. British Journal of Psychiatry, 167, 783-785.

V. MORGAN

D. CASTle

A. JABLENSKY

University of Western Australia

MRF Building, Level 3, Rear 50 Murray Street

Perth

Western Australia 6000

\section{Presenile dementia in a Down's syndrome adult with an unbalanced 21/21 Robertsonian translocation}

SIR: An association between Down's syndrome (DS) and Alzheimer's disease has now been well established (Oliver \& Holland, 1986). Virtually all DS subjects reported to date have had trisomy 21 karyotype. Rarely has Alzheimer-type dementia (ATD) been reported in non-trisomy $21 \mathrm{DS}$ individuals. Such rare cases include subjects with mosaicism (Rowe et al, 1989), 21/22 translocation (Sylvester, 1986) and 14/21 translocation (Prasher, 1993). I report ATD in a patient with a previously unreported unbalanced Robertsonian 21/21 translocation.

A 56-year-old woman with DS recently died following a five year history of gradual deterioration in her level of functioning. A history of progressive memory loss, mental confusion, abnormalities of speech, change in personality, mood 